\title{
LDRD FY 2014 Program Plan
}

August 2013

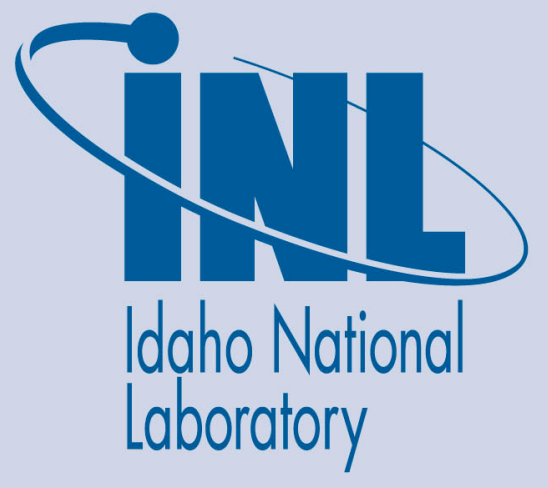

The INL is a U.S. Department of Energy National Laboratory operated by Battelle Energy Alliance 
INL/EXT-13-29519

\section{LDRD FY 2014 Program Plan}

August 2013

\section{Idaho National Laboratory Idaho Falls, Idaho 83415}

http://www.inl.gov

Prepared for the U.S. Department of Energy Through the INL LDRD Program Under DOE Idaho Operations Office Contract DE-AC07-05ID14517 


\section{LDRD Program Plan}

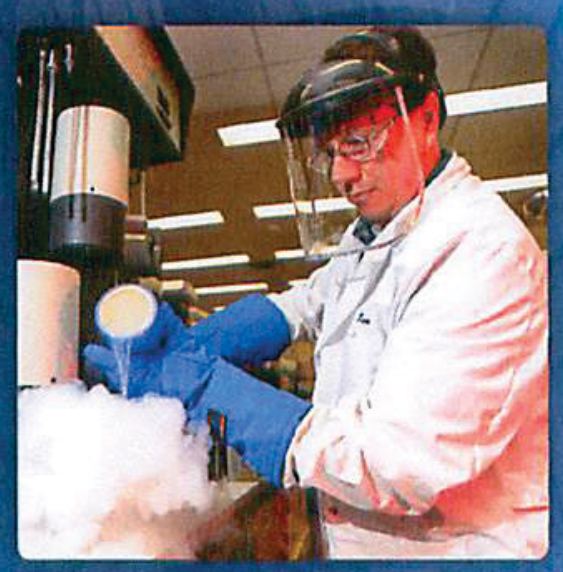

2014
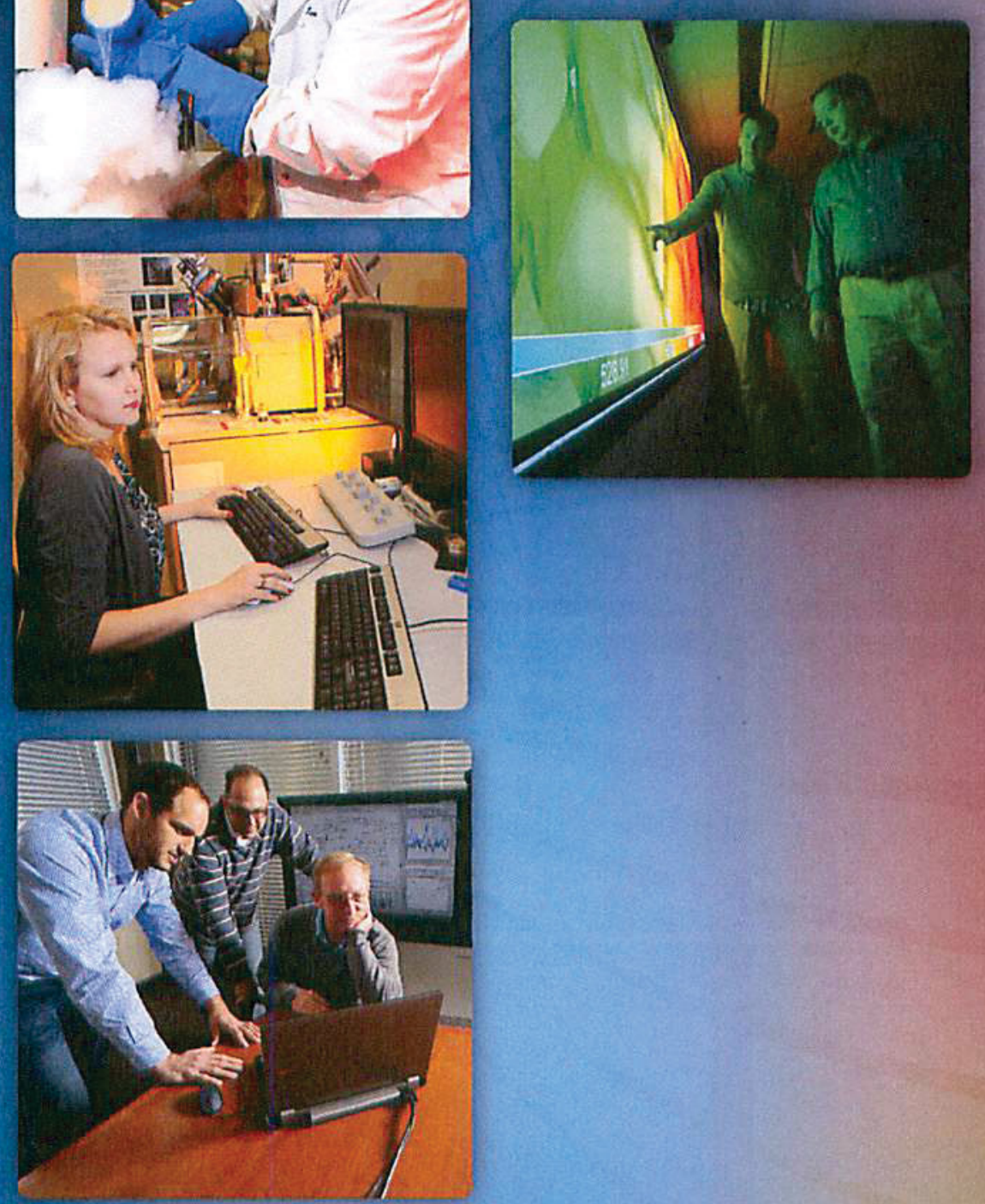

IIdaho National Laboratory 


\section{IDAHO NATIONAL LABORATORY •PLN 3872}

INL/EXT-13-29519

\section{INL LDRD FY 2014 PROGRAM PLAN}

Prepared by Idaho National Laboratory, Idaho Falls, Idaho 83415. Managed by Battelle Energy Alliance, LLC for the U.S. Department of Energy under contract DE-AC07-05ID14517.

Disclaimer: This report was prepared as an account of work sponsored by an agency of the United States Government. Neither the United States Government nor any agency thereof, makes any warranty, express or implied, or assumes any legal liability or responsibility for the accuracy, completeness, or usefulness of any information, apparatus, product, or process disclosed, or represents that its use would not infringe privately owned rights. Reference herein to any specific commercial product, process, or service by trade name, trademark, manufacturer, or otherwise does not necessarily constitute or imply its endorsement, recommendation or favoring by the United States Government or any agency thereof. The views and opinions of authors expressed herein do not necessarily state or reflect those of the United States Government or any agency thereof. 


\section{TABLE OF CONTENTS}

ACRONYMS

1

1. INTRODUCTION 1

2. INL LDRD AT A GLANCE .2

3. AUTHORIZATION. .3

4. INL LDRD PROGRAM DESCRIPTION 4

4.1 Alignment and Benefits. 4

4.1.1 INL Mission. 4

4.1.2 INL Vision 2020 4

4.1.3 INL LDRD Objectives .4

4.2 INL LDRD Portfolio 6

4.2.1 Nuclear Science and Technology .7

4.2.2 National and Homeland Security .10

4.2.3 Energy and Environment Science and Technology. .12

4.2.4 Center for Advanced Energy Studies .13

4.2.5 Institute for Nuclear Energy Science and Technology ...................13

4.2.6 Instrumentation, Control, and Intelligent Systems.

4.2.7 Crosscutting Capability Development......14

\section{LDRD PROGRAM ORGANIZATION AND} RESPONSIBILITIES. .15

5.1 Project Evaluation, Selection, and Review. .......15

5.1.1 Technical Evaluation of Proposals . . ....15

5.1.2 Management Evaluation of Proposals ...16

5.1.3 Project Selection and Approval. .........16

5.1.4 Review of Research Progress. ..........17

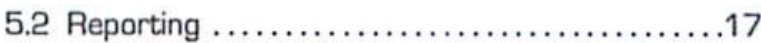

5.2.1 Monthly and Quarterly Budget Reports . . .17

5.2.2 Annual Report......................18

5.2.3 Annual Program Review. ..............18

5.2.4 Annual Report to Congress and Notification to Other Federal Agencies. . . .18

5.3 FY 2014 Program Schedule.................18

5.3.1 Technical Project Activities .............18

5.3.2 Program Management Activities.........18

5.4 LDRD Program Self Assessment .............19

\section{FIGURES}

Figure 1.

LDRD project alignment with INL R\&D objectives. . . . . ...5

Figure 2.

INL LDRD project review process to ensure

technical peer review and $R \& D$ objectives are met.. . . . .17

\section{TABLES}

Table 1.

INL R\&D Objectives.

Table 2.

The INL LDRD "Call" Routes to Access LDRD Funding....16 Table 3.

Approximate Dates of INL Technical Project

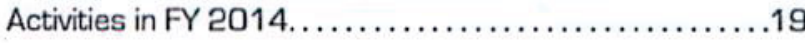

Table 4.

Dates of INL Program Management Activities.

Table 5.

LDRD Program Performance Measures

for Required Reporting Years. . .20 
IDAHO NATIONAL LABORATORY • PLN 3872 


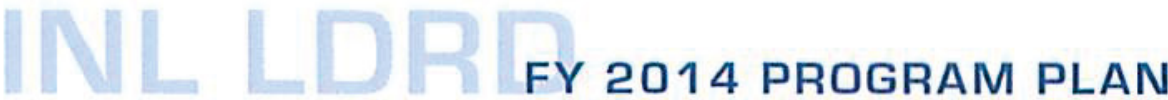

\section{INTRODUCTION}

This program plan describes the management and organization of the Laboratory Directed Research and Development (LDRD) program at Idaho National Laboratory (INL). The plan summarizes how the INL LDRD program benefits the Department of Energy (DOE), with focus on the Office of Nuclear Energy (DOE$\mathrm{NE}$ ), and other national programs as aligned with the INL multiprogram missions and strategic priorities. Section 2 provides a quick overview of LDRD fiscal information and metrics for fiscal year (FY) 2012. Section 3 provides the LDRD annual funding level request for FY 2014. Section 4 includes information on the proposed technical focus areas. Additionally, brief technical highlights from selected FY 2013 LDRD projects are provided to demonstrate the impact of the INL LDRD portfolio and its relevance to the INL Research and Development (R\&D) objectives, as well as its significant role in meeting the DOE mission. Section 5 describes the LDRD management and reporting processes and includes a schedule of key LDRD program activities and a program selfassessment.

This program plan was prepared in accordance with requirements in DOE Order 413.2B "Laboratory Directed Research and Development," and additional supporting guidance from DOE, including:
- "Roles and Responsibilities Guidelines for LDRD," Assistant Secretary for Nuclear Energy, issued January 6, 2009

- "Work for Others Notifications," Secretary of Energy, issued April 30, 2002

- "Application of Overhead Charges," Director, Office of Management, Budget and Evaluation/Chief Financial Officer, issued March 13, 2006.

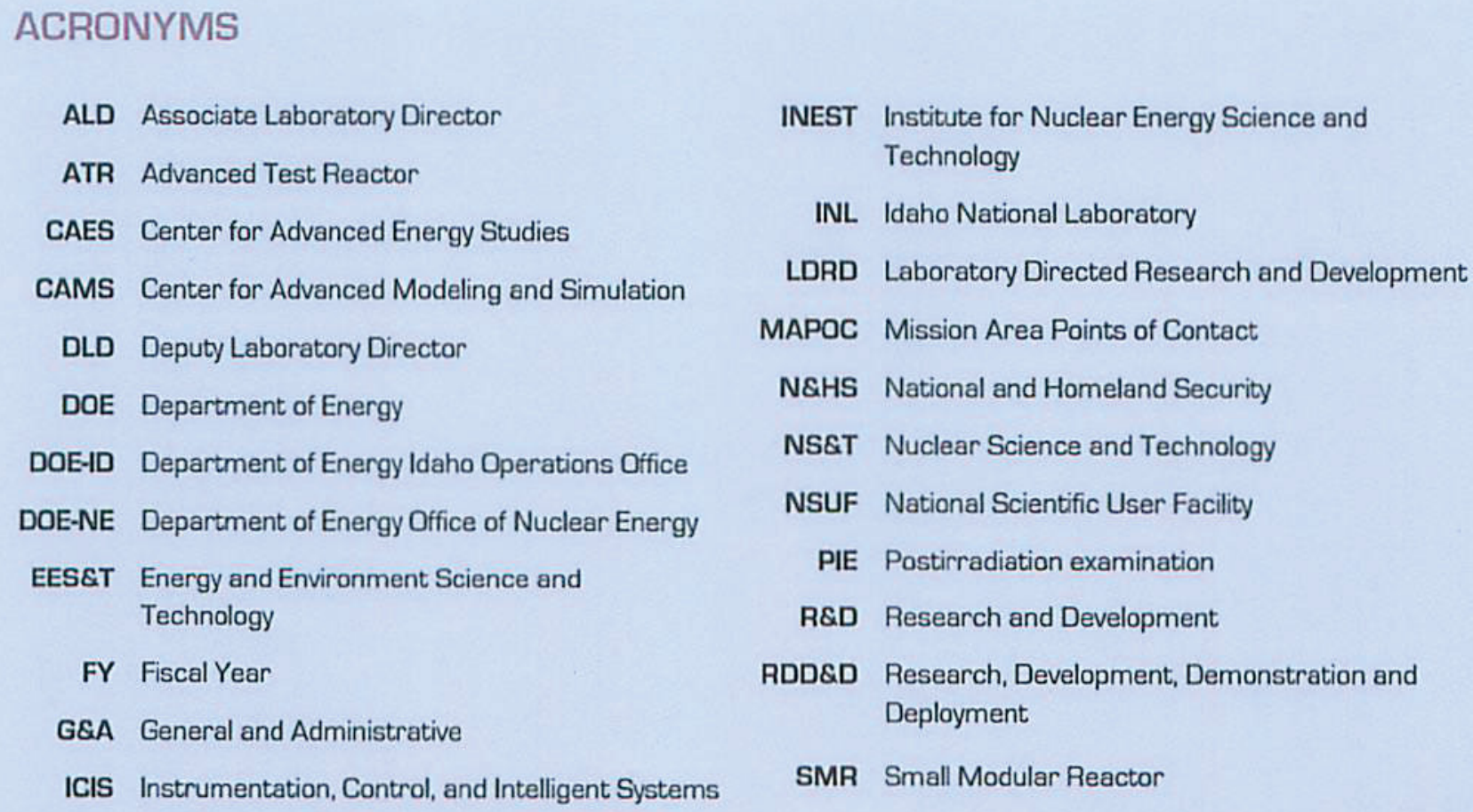

ALD Associate Laboratory Director

ATR Advanced Test Reactor

CAES Center for Advanced Energy Studies

CAMS Center for Advanced Modeling and Simulation

DLD Deputy Laboratory Director

DOE Department of Energy

DOE-ID Department of Energy Idaho Operations Office

DOE-NE Department of Energy Office of Nuclear Energy

EES\&T Energy and Environment Science and Technology

FY Fiscal Year

G\&A General and Administrative

ICIS Instrumentation, Control, and Intelligent Systems

INEST Institute for Nuclear Energy Science and Technology

INL Idaho National Laboratory

LDRD Laboratory Directed Research and Development

MAPOC Mission Area Points of Contact

N\&HS National and Homeland Security

NS\&T Nuclear Science and Technology

NSUF National Scientific User Facility

PIE Postirradiation examination

R\&D Research and Development

RDD\&D Research, Development, Demonstration and Deployment

SMR Small Modular Reactor 


\section{IDAHO NATIONAL LABORATORY • PLN 3872}

\section{INL LDRD AT A GLANCE}

\section{Location:}

Management Offices located in Idaho Falls, Idaho

Type:

Nuclear Energy, National Security, and Energy Security Multiprogram Laboratory

\section{Lead Program}

Secretarial Office:

DOE Office of Nuclear Energy

(DOE-NE)

\section{Contractor:}

Battelle Energy Alliance, LLC

\section{Responsible Site Office:}

DOE Idaho Operations Office (DOE-ID)

\section{Website:}

http://www.inl.gov

\section{LDRD Program Costs}

FY 2013 Anticipated

Funding Cap: \$28M

Projected Cost: $\$ 23 \mathrm{M}$

Projects: 89

\section{FY 2012 Final}

Final Cost: $\$ 28.4 \mathrm{M}^{*}$

Percent of INL Business

Volume: 3.17

Projects: 118

"Certified Cost base is defined in DOE Order $413.2 B$ and represents a laboratory's total operating and capital equipment budgets, including non-DOE funded work, but excluding certain cost categories where appropriate (e.g., Recovery Act costs).

\begin{tabular}{c}
\hline FY 2014 Budget Requested \\
Funding Cap: \$28M
\end{tabular}

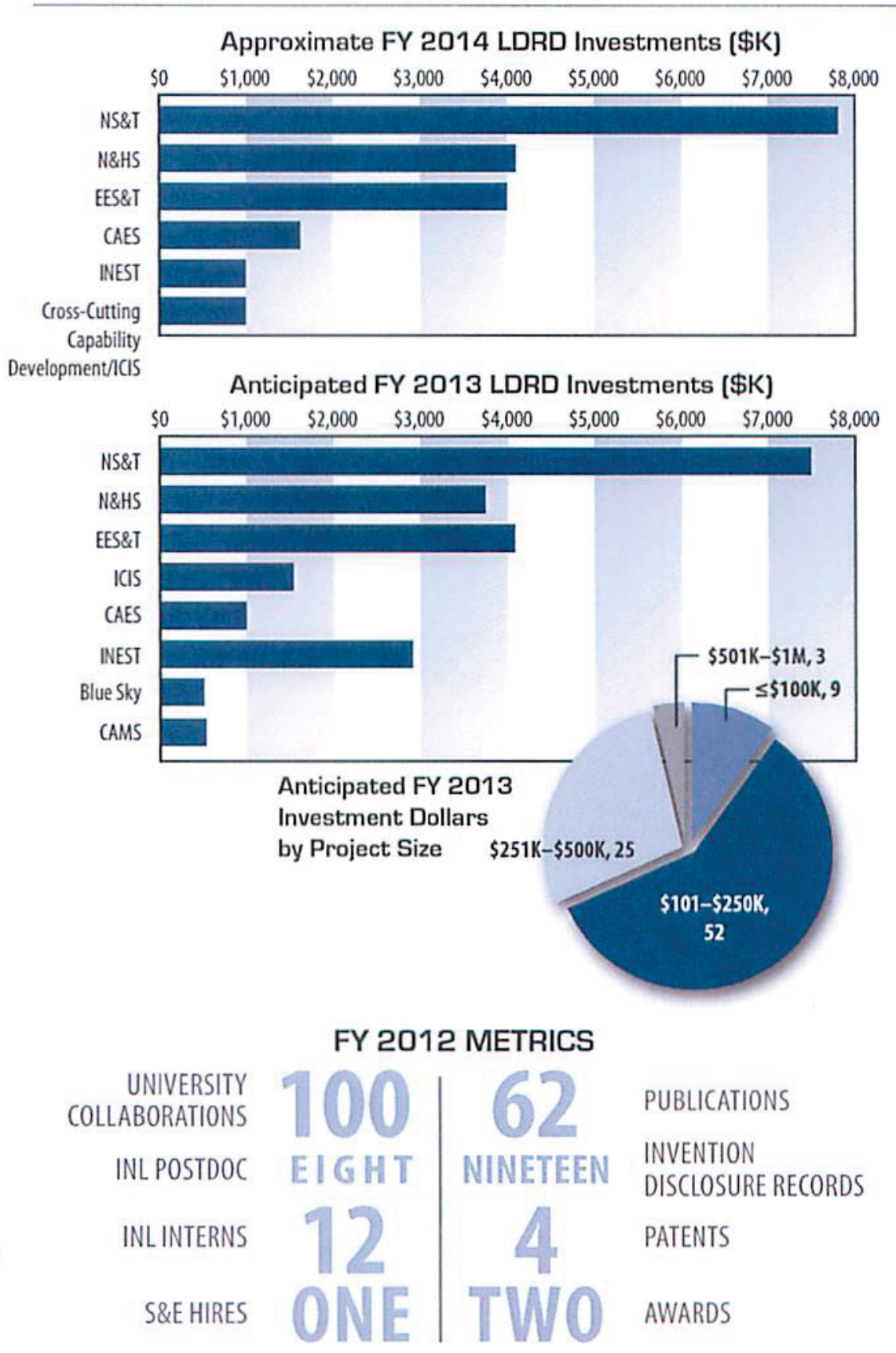




\section{FY 2014 PROGRAM PLAN}

\section{AUTHORIZATION}

The DOE Assistant Secretary, Office of Nuclear Energy, representing the DOE Cognizant Secretarial Office for INL, approves the INL LDRD Program Plan and annual funding level. DOEID concurs on each proposed and continuing LDRD project prior to project authorization. DOE-ID also concurs on significant changes that occur throughout the FY.

The annual LDRD budget is developed after careful consideration of investment needs and the overall INL indirect budget. The final LDRD budget request is developed and approved by the INL Laboratory Director. The INL LDRD funding level request is submitted via the annual LDRD Program Plan and is approved by DOE-NE following recommendations provided by DOE-ID.

This budget process complies with congressional direction as provided in the House Report 109-275 accompanying the Energy and Water Appropriations Act, 2006, Public Law 109-103. This supplementary guidance requires the application of overhead charges to LDRD in a manner that is consistent with fully burdening direct projects. In response to this supplementary guidance, LDRD funding was removed from the General and Administrative (G\&A) pool and established in a separate LDRD pool. The residual G\&A expenses (after removing LDRD from the G\&A pool) and other indirect costs are applied to LDRD activities in a manner consistent with their application to program activities.

\section{The annual LDRD budget is developed after careful}

\author{
consideration of investment needs and the affordability \\ within the overall INL indirect budget.
}

The INL Laboratory Director requests a FY 2014 funding level of $\$ 28 \mathrm{M}$ for the INL LDRD program. INL will initially allocate approximately $\$ 20 \mathrm{M}$ to the LDRD program, which may change based on the review of FY 2014 congressional appropriations and overall INL budget status during the first half of FY 2014, but will not exceed \$28M without DOE approval. The requested funding level is estimated to be approximately three percent of total projected Laboratory costs, which is below the legally mandated eight percent upper limit for LDRD. The FY 2014 budget allocation request remains at approximately three percent (the same percentage as FY 2012 and FY 2013) even though the dollar allocation amount has decreased. The INL's base funding level has decreased and is anticipated to be at a lower level again in FY 2014. 


\section{IDAHO NATIONAL LABORATORY • PLN 3872}

\section{INL LDRD PROGRAM DESCRIPTION}

\subsection{Alignment and Benefits}

The purpose of INL's LDRD program is to develop and execute a diverse R\&D portfolio that ensures capabilities are in place to support DOE's current and future missions. The LDRD program at INL is aligned with the Laboratory's mission and vision, ensuring focus and investments are consistent with strategic priorities agreed upon with DOE-ID and DOE-NE.

\subsubsection{INL Mission}

INL is the Nation's preeminent nuclear energy laboratory with synergistic world-class multiprogram capabilities and partnerships. INL provides scientific and engineering solutions to meet the Nation's energy security and prosperity challenges by addressing nuclear R\&D, national and homeland security, energy sustainability, and energy security technical needs.

\subsubsection{INL Vision 2020}

By 2020, INL will build a laboratory that serves the Nation and will be enduring as the National Nuclear Laboratory with the following attributes:

- Leads and integrates technical programs of national significance

- Hosts collaborative connections to universities, labs, industry, and international research institutions

- Provides distinguished research as a multiprogram laboratory applying INL capabilities to sustain and broaden the R\&D base
- Reinforces INL's capabilities, facilities, and infrastructure as the national nuclear capability.

\subsubsection{INL LDRD Objectives}

The primary DOE-NE mission is to advance nuclear power as a resource capable of meeting the Nation's energy, national security, and environmental needs by resolving technical, cost, safety, proliferation resistance, and security barriers through research, development, demonstration, and deployment (RDD\&D), as appropriate. The INL LDRD portfolio objectives, as outlined in the DOE order, are to:

- Maintain the technical vitality of the Laboratory

- Foster creativity and stimulate exploration at the forefront of science and technology

- Serve as a proving ground for new research

- Support high-risk, potentially highvalue R\&D.

The LDRD program provides visionary, cutting-edge science and innovative technologies to support DOE's missions and serves as an incubator for high-value ideas that uniquely enrich DOE-NE research as a whole. The LDRD program is indispensable as a catalyst for scientific innovation and enhancement of the technical capabilities necessary to support DOE's current and future missions. It is an essential capability-building program that strengthens competency; attracts and maintains world-class researchers; and cultivates collaborative networks with universities, industry, and other laboratories.

The approved FY 2013 INL

Laboratory Plan, at the request of the Under Secretary of Energy, unites the INL R\&D vision and core capabilities with the INL Ten-Year Site Plan. These two plans provide a framework that guides and supports Laboratory planning, resource development, program execution, and discretionary investments. The INL LDRD Program Plan is aligned with these documents.

The INL has defined six core R\&D objectives in the INL Laboratory Plan that will focus INL's efforts to help shape the future of nuclear energy technology, national and homeland security, and energy security for our Nation. These objectives are spelled out in Table 1. Each element of the LDRD portfolio aligns with at least one of the INL R\&D objectives (in some cases, two or three of the objectives). Although it is not imperative that an LDRD project have strict alignment, an LDRD project should support the INL vision, contribute to enhancing important capabilities, and maintain the technical vitality of the Laboratory.

Figure 1 provides a closer look at the R\&D objectives and a percentage approximation of how many of the FY 2012 and FY 2013 LDRD projects align with each R\&D objective, recognizing that some LDRD projects 


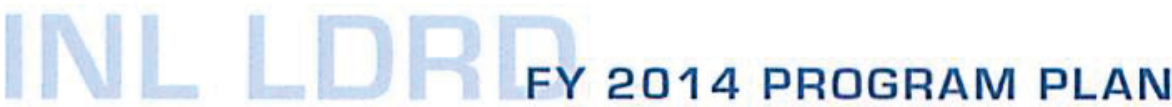

have been mapped to more than one R\&D objective. The alignment of our diverse INL LDRD investment portfolio is consistent with the strategic mission of the Laboratory that builds capabilities, expands our knowledge base, and enhances our scientific stature and national impact while meeting the current and future mission of DOE. The FY 2014 portfolio grouping will likely be very similar to the FY 2013 portfolio distribution.

\begin{tabular}{|c|c|}
\hline $\begin{array}{l}\text { R\&D } \\
\text { Objective }\end{array}$ & Challenge \\
\hline 1 & $\begin{array}{l}\text { Develop technologies that extend the life, as well as improve performance and sustain the safety, of the } \\
\text { current fleet of reactors }\end{array}$ \\
\hline 2 & Improve reactor designs so reactor systems are more affordable, safe, effective, and efficient \\
\hline 3 & Manage the nuclear fuel cycle so it is more effective and reduces waste and costs \\
\hline 4 & Understand and minimize risks of nuclear proliferation and terrorism \\
\hline 5 & Develop means to protect the Nation's critical infrastructure systems and defense systems \\
\hline 6 & Advance the deployment of secure and sustainable energy systems \\
\hline
\end{tabular}

\begin{tabular}{|c|c|c|}
\hline FY $-12-16 \%$ of projects & FY $13-16 \%$ of projects & $\begin{array}{l}\text { Sustain the safety, reliability, and lifetimes of } \\
\text { current reactors }\end{array}$ \\
\hline FY $12-18 \%$ of projects & FY $13-16 \%$ of projects & $\begin{array}{l}\text { Improve reactor designs so reactor systems are } \\
\text { more affordable, safe, effective and efficient }\end{array}$ \\
\hline FY $12-13 \%$ of projects & FY $13-13 \%$ of projects & $\begin{array}{l}\text { Manage the fuel cycle so it is more effective and } \\
\text { reduces waste and costs }\end{array}$ \\
\hline FY $12-7 \%$ of projects & FY $13-8 \%$ of projects & $\begin{array}{l}\text { Understand and minimize risks of nuclear } \\
\text { proliferation and terrorism }\end{array}$ \\
\hline FY $12-16 \%$ of projects & FY $13-11 \%$ of projects & $\begin{array}{l}\text { Develop means to protect the Nation's critical } \\
\text { infrastructure and defense systems }\end{array}$ \\
\hline FY $12-30 \%$ of projects & FY $13-36 \%$ of projects & $\begin{array}{l}\text { Advance the deployment of secure and } \\
\text { sustainable energy systems }\end{array}$ \\
\hline
\end{tabular}




\section{IDAHO NATIONAL LABORATORY • PLN 3872}

\subsection{INL LDRD Portfolio}

Appointed by the Laboratory Director, the INL Deputy Laboratory Director (DLD) for Science and Technology guides the INL LDRD program to ensure the overall mission and goals are consistent and aligned with DOE Order 413.2B "Laboratory Directed Research and Development." The LDRD research portfolio objectives are developed by assessing the capabilities and technical initiatives needed to support current and future DOE and national needs. The DLD and the three INL Associate Laboratory Directors (ALDs) engage strategic planners, mission area points of contact (MAPOC), and the LDRD Program Manager to further establish the Laboratory's LDRD portfolio. These internal collaborations ensure strategic alignment of the LDRD portfolio with Laboratory mission objectives. The LDRD request for proposals (the Call) conveys approximate target funding allocations and a strategic annual call for proposals. Maintaining and ensuring the technical vitality of the Laboratory is reinforced during individual LDRD project selection, progress reviews, and external peer advisory committee reviews. Annually, selected LDRD projects are reviewed by an external peer advisory committee. These committees validate the LDRD investments are aligned with INL's mission and vision; are innovative, cutting-edge $R \& D$ projects; and are technically sound.
The INL of today is the core of the National Nuclear RDD\&D capability and offers an irreplaceable array of capabilities in nuclear engineering and related scientific disciplines such as, materials science, nuclear and radiochemistry, chemical engineering, systems engineering, decision analysis, and probabilistic risk assessment, as well as purposebuilt research infrastructure for nuclear energy RDD\&D. The INL LDRD portfolio - with its diverse competencies in Nuclear Science and Technology (NS\&T), National and Homeland Security (N\&HS), and Energy and Environment Science and Technology (EES\&T) - serves the energy challenges and energy security concerns of today with highly creative, innovative, and impactful R\&D activities. The research activities support multiple DOE offices, the National Nuclear Security Administration, and other agencies, such as the U.S. Department of Defense, the U.S. Department of Homeland Security, the Nuclear Regulatory Commission, and the National Aeronautics and Space Administration. The portfolio provides a framework for focusing enhancement of existing staff and attracting additional world-class talent to INL. The INL LDRD portfolio is designed to anticipate and respond to the challenges ahead by providing $R \& D$ projects at the forefront of science and technology relevant to the DOE mission.

The FY 2014 portfolio will continue to be strategically directed toward the DOE-NE mission and synergistic multiprogram capability development with an emphasis on strategic hires, including postdoctoral candidates, prominent researchers, and junior researchers crucial to meeting the Laboratory's future mission expectations. With continued focus on the six INL R\&D objectives, the LDRD portfolio will be distributed through the INL focus areas in NS\&T, N\&HS, EES\&T, Center for Advanced Energy Studies (CAES), Institute for Nuclear Energy Science and Technology (INEST), and a Crosscutting Capability Development LDRD portfolio. The Blue Sky, Ph.D., Center for Advanced Modeling and Simulation (CAMS), and Engineering portfolio (all commonly referred to as enabling portfolio) focus areas have been removed from the FY 2014 portfolio. Even though the FY 2014 Call did not include the enabling business portfolios, the concepts, principles, and objectives from the enabling focus areas were included in the directorate focus areas. A FY 2014 new Crosscutting Capability Development portfolio has been added. This portfolio area was created specifically to create crossdirectorate teams to utilize expertise and capabilities across the Laboratory to provide RDD\&D leadership needed to enable the future electric power grid and the efficient integration of renewable and traditional energy systems. Each portfolio focus area is described below along with highlights of ongoing or previous LDRD projects to demonstrate impact and alignment to the overall INL R\&D objectives. 


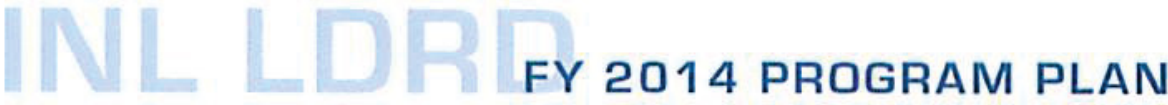

\subsubsection{Nuclear Science and Technology}

The focus of NS\&T's portfolio is on the development and evaluation of nuclear fuels, reactors, and fuel cycle technologies. These capabilities include the Advanced Test Reactor (ATR), a highly flexible materials test reactor, and associated fuel development capabilities including fabrication, characterization, and postirradiation examination capabilities. Strategic focus areas include:

\section{Fuel \& Materials Modeling and Simulation}

MOOSE Simulation Framework LDRD Legacy 11-061, 10-017, 09-113, 08-071

\section{Mission Relevance:}

- Lead R\&D efforts for nuclear energy technologies to help meet our Nation's energy and environmental challenges

- Conduct R\&D in crosscutting technologies that directly support the development of new and advanced reactor designs and fuel cycle technologies

Technical Impact:

- The MOOSE simulation framework has revolutionized predictive modeling in an array of scientific fields

- Reduces the cost and time required to develop new nuclear fuel forms

- Provides a behavioral understanding of the nuclear fuel at high burn-up

- State-of-the-art modeling and simulation of nuclear fuel
- Fuels \& Materials R\&D and Modeling and Simulation: The objective of this focus area is to develop transformational fuel cycle technologies in the following areas: (1) advanced fuel fabrication techniques for metal fuels, ceramic fuels, and composite fuels, (2) advanced measurement techniques to characterize fresh and irradiated fuels at microstructural level, (3) on-line instrumentation for inpile experiments, (4) innovative

performance including 3D behavior or application to new fuel materials, new designs, or extended fuel burn-up

- Used as the basis for INL's engineering scale fuel performance code BISON and mesoscale fuels code MARMOT

Awards:

- Derek Gaston recipient of Presidential Early Career Award for Scientists and Engineers

Licenses:

- 38 active software license agreements

- 20 Universities licensed MOOSE and MOOSE-based applications in 18 states, 4 national laboratories, 7 private companies, and 6 foreign entities ideas for out-of-pile testing of fuels and materials for targeted phenomenology, (5) innovative ideas for analyzing the postirradiation examination data, and (6) innovations in coated particle fuel. Innovative proposals that couple experimental studies with multiscale, multi-physics modeling methods that enhance the ability to accurately quantify and predict nuclear fuel performance and advance the scientific understanding of nuclear fuels are an area of investment.

- Used Fuel Disposition: The goal of this R\&D area is to couple multiphysics modeling/simulation with uncertainty quantification to provide a framework for the evolution of the testing and validation program that will be required to develop the long-term dry storage technical justification. The R\&D efforts will focus on used fuel testing, analysis, and decision-making to determine the viability of developing a descriptive model for used nuclear fuel in dry storage. This supports INL's nuclear energy leadership role by advancing applied nuclear engineering modeling and 


\section{Fuel Cycle Separations LDRD Achievement}

Utility of Unusual Oxidation States

of Americium for Separations - LDRD

07-010 (completed project)

\section{Mission Relevance:}

- Advance the state of nuclear technology by improving its competitiveness

- Contribute to solving our Nation's energy and environmental challenges

- Conduct R\&D that fosters innovative and transformational technology solutions to design a "fully closed" nuclear fuel cycle that is proliferation resistant

\section{Developing New Capabilities}

Induction Based Fluidic Mass Spectrometry for Characterizing Radioactive Extraction Solvents LDRD 13-039

Mission Relevance:

- Advance the state of nuclear technology by improving its competitiveness

- Contribute to solving our Nation's energy and environmental challenges

Innovative and Novel:

- Mass spectrometry (MS) technology developed to enable measurement of nanoliter size sample volumes

- Overcomes the problem of electrostatic droplet repulsion in conventional electrospray sample introduction systems
Technical and Mission Impact:

- A lanthanide separation proof-ofprincipal effort to oxidize Am to the Am6+ valence state

- Resulted in FCR\&D NE direct funding under the DOE sigma team for minor actinide separations program - approximately \$3M since 2009

- Am separations process flow sheet under consideration for deployment in advanced fuel cycle

- Peer-reviewed publications in Inorg. Chem. and Chem. Rev.

- INL maintains technical expertise in actinide and lanthanide separations by fostering creative chemical approaches for nuclear separations (LDRD 11-005, 11-023, 12-059) simulation capabilities to ensure safe, reliable, and higher economic performance of the existing fleet of nuclear reactors.

- Reactor Safety and Simulation: The R\&D activities in this focus area are directed at advancing applied nuclear engineering modeling and simulation capabilities to ensure safe, reliable, and higher economic performance of the existing fleet of nuclear power plants and to enable rapid deployment of advanced systems.

The R\&D goals will be accomplished by accepting proposals in the topical areas of advanced small modular reactor (SMR) designs and new safety paradigms, methodologies and tools for verification and validation, SMR thermal hydraulic experimentation and analysis, nuclear reactor core modeling and simulation, and accident-tolerant sensors.

Technical Impact:

- Rare earth and nuclear fuel reprocessing analyses

- Analytical Chemistry publication June 6, 2013

- Collaboration with industry

- ATR National Scientific User Facility (NSUF) Capabilities: The intent of the ATR NSUF technical focus area is to expand nuclear R\&D facility experimental capabilities

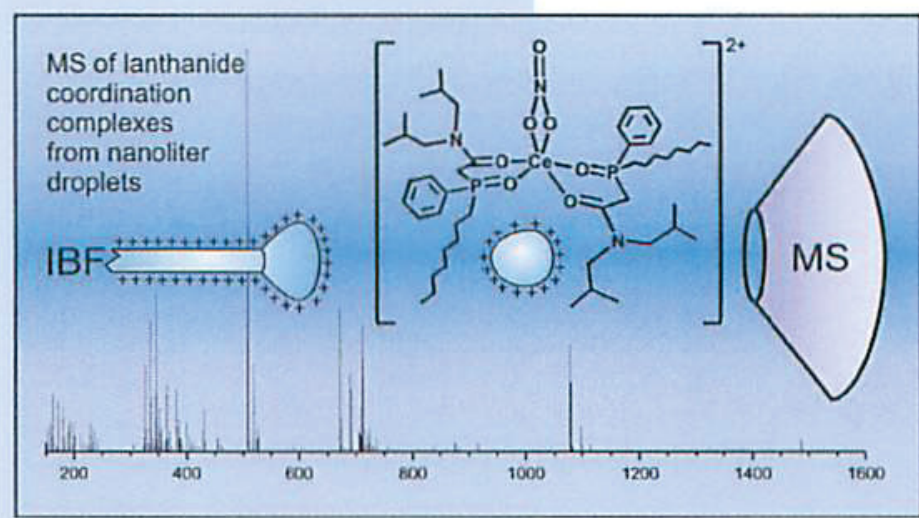




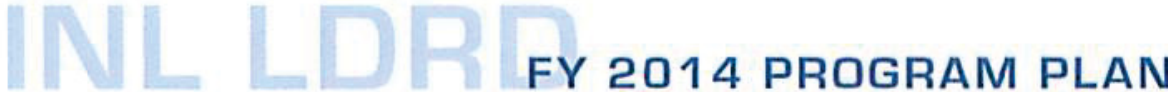

including new instrumentation, techniques, advanced in-reactor instrumentation, or other experimental capabilities to enhance INL's nuclear and non-nuclear $R \& D$ programs. The $R \& D$ projects will be related to development of advanced in-reactor instrumentation for experiments and innovative postirradiation examination (PIE) capabilities that address challenges associated with testing of large numbers of highly irradiated samples.

- Fuel Cycle Separations and Waste Forms: The intent of this technical focus area is to develop new capabilities that advance separation processes, waste forms, and strategic material recovery from a wide variety of sources. The focus area is aimed at: (1) advanced aqueous separation methods for used nuclear fuel, (2) advanced pyrochemical separation methods, (3) critical and strategic material separation, and (4) process development and demonstration for national security applications.

- Space Nuclear Systems: The R\&D activities in this focus area seek to develop advanced technologies for use in a reactor environment that could be used to support the enhanced production of radioisotopes for power generating systems; power conversion technology development to enhance the current efficiencies, size, or mass of the overall systems; and "game changing" power technologies that are applicable for space environments.
- Probabilistic Risk Assessment and Related Methods: The LDRD projects in this technical focus area aspire to develop concepts at the forefront of probabilistic risk assessment and management, human factors, and human reliability analysis. These technical topics are important in the advancement of risk assessment, reliability engineering, and system safety analysis.

INL LDRD projects aim to provide revolutionary approaches that are needed to shape not only the future of nuclear energy technology but also the

\section{Critical Infrastructure \& Defense Systems}

Metal Fluoride Preparation for Accelerator Mass Spectrometer Analyses - LDRD 13-060

\section{Mission Relevance:}

- Develop technology research and testing capabilities that enhance our national leadership role in ultratrace mass spectrometry measurements to address needs for DOE and other national security organizations

- Aligned with INL R\&D Objective Three-Enable Sustainable Fuel Cycles and with INL R\&D Objective Four-Understand and Minimize Risk of Nuclear Proliferation and Terrorism

Innovative and Novel:

- Proof of principle to improve the capability to measure actinides in environmental samples future well-being and energy security of the Nation, conducting research to transform and fundamentally alter how nuclear energy is deployed.
- Dissolution of a wide range of refractory matrices typical of nuclear explosion debris yields a class of measurable molecular species known as "super halides"

Technical Impact:

- A highly attractive feature of this approach is that the isotopic ratio signatures collected during mass measurements is derived solely from the isotopic abundance of the actinide

- Deployment of the new method will lead to a significant reduction in costs for postirradiation analysis of nuclear fuels research, nonproliferation safeguards measurements, and forensic analysis of environmental samples

- Publication submitted to Analytical Chemistry

Collaborations:

- University of Idaho

- Osaka University 


\section{Enhancing Security and Resiliency \\ Geomagnetic Disturbance Field Coupling Measurements - LDRD 13-118}

\section{Mission Relevance:}

- Develop technology research and testing capabilities that enhance our national leadership role and meet needs for DOE and other national customers

- This project is aligned with INL R\&D Objective Five-Critical Infrastructure Protection and Defense Systems

Innovative and Novel:

- Configuring an array of sensors to monitor experiments on the INL Power Grid Testbed to correlate effects from ground induced currents (GIC) caused by geomagnetic storms

- Collect GIC measurements from three-phase alternating-current high-voltage and mediumvoltage INL transformers, transmission lines, and other power infrastructure along with co-located geomagnetic effect sensors

Technical Impact:

- Experimental data will be used to develop deployable technology solutions that can be used by electrical utilities to protect against grid transformer damage that may result from geomagnetic disturbances (GMD)

- Results from the experiments will be included in an August, 2013 national GMD symposium at INL

\subsubsection{National and Homeland Security}

The N\&HS mission is to develop technology research and testing capabilities to establish a national leadership role in nuclear nonproliferation, critical infrastructure protection and the deployment of secure and sustainable energy systems. Strategic focus areas include:

- Nuclear Nonproliferation: The objective of this focus area is to advance nonproliferation technologies that address minimizing proliferation and security risks associated with nuclear energy. Research is focused on advanced concepts for solutions that integrate the combined principles of safeguards, safety and security, including cybersecurity, into nuclear energy facilities. INL is also building technical capabilities that support the current and future international safeguards and nonproliferation objectives of DOE. LDRD is related to the detection and characterization of special nuclear materials, detection and characterization of proliferation signatures and observables, preparation and

\section{Critical Infrastructure \& Defense Systems}

Polymer Components in Armor Systems for Ballistic Protection - LDRD 12-017

Mission Relevance:

- Develop technology research and testing capabilities that enhance our national leadership role to meet needs for DOE and other national customers

- Provide innovative approaches for armor development and testing to protect the war fighter

- This project is aligned with INL R\&D Objective Five-Critical Infrastructure Protection and Defense Systems

Innovative and Novel:

- Explore the gap between passive and explosive-reactive armor categories

- Incorporate polymers in multi-layer armor designs to dissipate ballistic shock-waves
- Use polymers to enable ceramics' capability to provide multi-hit protection

Technical Impact:

- Provided new test method to reduce cost of armor $R \& D$ testing by $50-75 \%$

- Developed and validated analytical tools to predict thermal environment needed by polymers to endure ballistic impact

- Provided armor solutions that are more mass efficient than current standards

- Engineered an approach to affect the dispersion of shock waves through a stacked medium

- Collaboration with Washington State University

- Peer-reviewed technical publication submitted to ASTM J. Test. Eval.

- Three publications pending 
training of safeguards professionals, and preparation and training of emergency responders to nuclear/ radiological threats. These research activities build differentiating capabilities and recognition for INL while enabling the secure, trusted, and economical global deployment of nuclear energy systems.

- Critical Infrastructure Protection: This technical focus area will emphasize the development of novel solutions for achieving cybersecurity and resiliency of industrial control systems, information assurance and spectrum sharing for wireless communication, and reliability and security of the U.S. electric power grid. Key projects will focus on the prevention, detection, and mitigation of physical threats to infrastructure from natural disasters or vulnerability/threats. Additionally, $R \& D$ projects may focus on advancing the protection of military infrastructure or aid the war fighter. Research areas include projects that implement a science-based approach for assessing critical system component vulnerabilities. Research will develop unique and deployable techniques for effective mitigation or risk management that improve operation integrity and system cybersecurity with an emphasis on protecting the electric power grid and nuclear energy infrastructure.
- Defense Systems: The focus of this technical area is on proof of principle concepts that result in novel combinations of materials with the potential to enhance asset performance and protection against emerging threats.

INL LDRD projects are enhancing the technical vitality of the Laboratory by supporting the Nation's goals for global security by ensuring the protection of a reliable supply of energy, including safe and secure nuclear energy. As the National Nuclear Laboratory, INL leverages its rich nuclear R\&D heritage and enduring fuel cycle expertise to

\section{Critical Material Technologies}

\section{Development of Unique}

Nanomaterials for Selective

Replacement of Strategic \& Critical

Materials - LDRD 12-093

\section{Mission Relevance:}

- Advance new energy technologies into the commercial marketplace

- Introduce technologies which enable reduction, reuse, recycle, and recovery of energy critical elements

Innovative and Novel:

- Builds upon INL R\&D 100 Award winning technology

- Synthesis of new, novel core-shell nanomaterials used as lightemitting sources for solid-state Light-Emitting Diodes (quantumdot LEDs) provide leadership in the minimization of nuclear proliferation risk, effective safeguarding against material diversion for non-peaceful purposes, and enhanced security protecting the Nation's critical infrastructure.
- Novel core-shell nanomaterials chemistry that allows for replacement of critical material lanthanides in energy-efficient lighting phosphors and tunable band-gap engineering

Technical Impact:

- Inexpensive replacement of strategic and critical elements

- Rapid advancement of energyefficient solid-state lighting

- Anticipated peer-reviewed publication in 2013

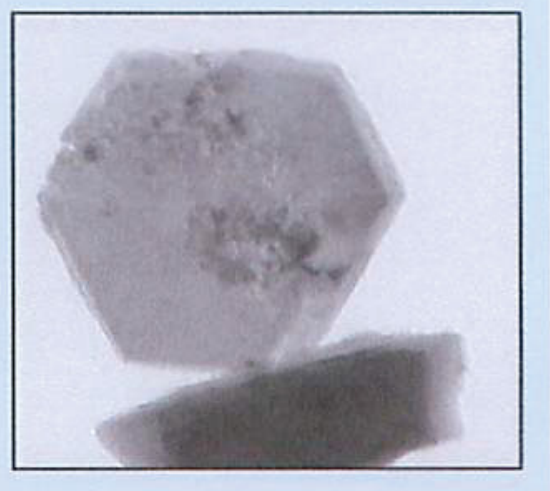




\section{IDAHO NATIONAL LABORATORY • PLN 3872}

\subsubsection{Energy and Environment Science and Technology}

The EES\&T mission is to advance U.S. energy security and industrial competitiveness through science-based performance assessment, advanced process science and technology, and systems integration and engineering.
This portfolio area is designed to help integrate clean energy into the electrical grid by expanding the role of nuclear energy through non-traditional uses. Additionally, EES\&T projects aim to improve the safety, affordability, and performance of electric vehicles; advance the development of biofuels

\section{Advancing Process Technology \\ Hybrid Osmosis Water Purification Systems Research - LDRD 10-092 \\ Mission Relevance: \\ - Advance new energy technologies into the commercial marketplace. \\ - Introduce technologies which enable reduction, reuse, recycle, and recovery of energy critical elements \\ Innovative and Novel: \\ - Patent-pending process to purify water from extremely concentrated solutions, (salts, organics, inorganics, biologics) \\ - Leverages the switching qualities of carefully selected specialized thermolytic salts}

- Switchable polarity solvents materials can be recycled in the switchable polarity solvents forward osmosis process many times due to their inherent chemical stability

- Potential to dramatically increase the availability of fresh water supplies through sea water and brackish water desalination, reduction of industrial water usage and treatment of waste water discharge

Impact:

- Recipient of 2013 R\&D 100 Award

- INL has signed two license option agreements with major companies within the forward osmosis segment of the water processing industry and synthetic fuels to reduce the country's dependence on foreign fossil fuels; and refine science-based predictive techniques to reduce the environmental impact of energy extraction operations. The EES\&T portfolio works to solve the key technological challenges identified by DOE as critical to national energy security. Specific technical areas include:

- Energy Systems Technology: The objective of this focus area is to establish new testing capabilities and approaches that leverage existing INL capabilities associated with nuclear reactor and power systems development, advanced transportation, electric vehicles and energy storage system analysis and testing, clean energy technology testing, and the Instrumentation, Control, and Intelligent Systems (ICIS) LDRD portfolio. This LDRD focus area will complement the FY 2014 Crosscutting Capability Development LDRD portfolio to develop dynamic energy systems and computation, simulation, and

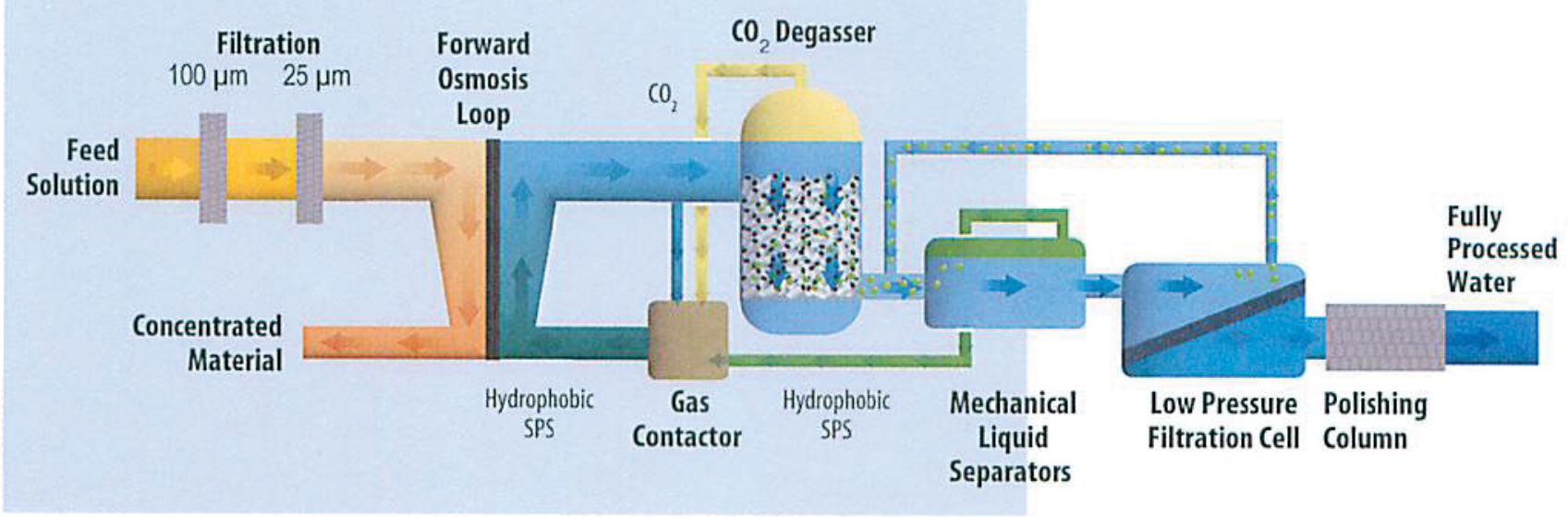


control tools. Working together, these capabilities will help address high impact challenges associated with transformation of the electrical grid to a tightly-coupled hybrid energy system that will enable a higher penetration of renewable and nuclear energy. This investment area will focus on R\&D activities that specifically address the challenges of grid integration with energy storage systems, focusing on (1) energy storage systems that would enhance wind, electricity and solar energy production and distribution, or (2) thermal energy storage that would enhance the efficiency and reliability of distributed, small-scale thermal generation sources such as concentrated solar or small-modular nuclear reactor power plants. Investments may include new or enhanced experimental capabilities which incorporate supervisory control/data acquisition capable of simulating real-time integration of the storage system with realistic electrical grid and/or thermal energy use options (including power generation).

- Advanced Energy Storage: The intent of R\&D activities in this focus area is to foster the development of advanced batteries that will contribute to ensuring domestic energy security. There is an emerging need to develop advanced battery monitoring and management systems that can extend useful battery life, increase performance capability, improve safety, and provide useful information for secondary use applications. In addition, R\&D activities are aimed towards: (1) proof of principle of advanced battery materials that can be synthesized, characterized, and tested in working rechargeable batteries; (2) the characterization of advanced battery materials in terms of situ techniques that are amenable to fuel cells; and (3) larger scale battery systems that have portable power grid applications.

- Advanced Mamufacturing: This technical area focuses on the development of advanced manufacturing technologies and processes that explore (1) sustainable manufacturing including recycling and remanufacturing, (2) biomanufacturing production of commodity goods and (3) advanced materials production.

- Energy Security Blue Sky: This focus area is aimed at "out-of -the box," high risk, potentially high value R\&D projects that do not necessarily fit into the EES\&T focus areas above but have the potential to address key technological challenges identified by DOE as critical to national energy security.

\subsubsection{Center for Advanced Energy Studies}

The CAES investment involves teams from Idaho universities and INL who undertake research projects in support of the DOE energy mission. In addition to executing high-quality, innovative research, these INL-led collaborative research partnerships are an essential element of the INL human resource development strategy that attracts, engages, and retains the best and brightest undergraduate and graduate students and faculty and continuously renews the scientific workforce in Idaho and for the Nation.

\subsubsection{Institute for Nuclear Energy Science and Technology}

The INL INEST portfolio, like the CAES portfolio, teams with university partners to solve complex national problems. However, INEST projects team with key nuclear universities. The INEST portfolio seeks to provide the technical knowledge to help define the long-term direction of the Nation's nuclear energy program and prepare the next generation of nuclear scientists and engineers. Current projects are focused on nuclear fuels and materials, nuclear fuel cycles, nuclear power system safety and licensing, space nuclear power, and uses of hybrid nuclear energy systems.

\subsubsection{Instrumentation, Control, and Intelligent Systems}

The ICIS distinctive signature integrates control theory, cyber security, and human systems $R \& D$ required to understand, predict, and plan for system efficiency and resilient recovery of control systems. Research will address failures or loss in performance of equipment in nuclear energy facilities, energy distribution, industrial processes, waste management, and other critical infrastructure assets. Focus areas include intelligent and threat-resilient control systems, unique and revolutionary sensor detection methods, autonomous distributed control architectures, cyber-physical security attack recognition, energy dispatch and power efficiency optimization algorithms, and core 


\section{IDAHO NATIONAL LABORATORY • PLN 3872}

technologies necessary to achieve a "Smart Grid."

\subsubsection{Crosscutting Capability Development}

A new Crosscutting Capability Development portfolio area has been developed for FY 2014. This focus area was specifically created to utilize cross directorate expertise to provide RDD\&D leadership needed to enable the future electric power grid and the efficient integration of renewable and

\section{INEST}

Microstructural Evolution of $\mathrm{UO}_{2}$ and $U$ under Irradiation - LDRD 10-058 (completed project)

\section{Mission Relevance:}

- Advance the state of nuclear technology by improving its competitiveness and promoting continued contribution to meeting our Nation's energy and environmental challenges

\section{Technical Impact:}

- Non-destructive technique which is sensitive to open volume defects, such as vacancies, void, and dislocations

- Optimal for examining irradiation damage in materials

- Provides technical data needed for nuclear fuel design and performance modeling

- Suite of instrumentation will be utilized by the ATR-NSUF researchers

Collaboration:

- Washington State University traditional energy systems. Expertise in nuclear reactor and thermal hydraulic systems, renewable energy systems, electrical power transmission and distribution, industrial control, cyber security, instrumentation and intelligent controls, modeling, simulation, and validation will be brought together. The unique INL capabilities such as the isolated dual fed power grid, the Wireless Test Bed, and real time digital simulation systems will form a robust foundation for addressing the national electric power grid and energy integration technical challenges facing our nation.

\section{Instrumentation, Control, and Intelligent Systems}

Battery Resilient Monitoring and Control-LDRD 12-071

Mission Relevance:

- Contributes to advancing the deployment of secure and sustainable energy systems for the Nation

- Optimizes battery use for transportation and power sectors

- Aligns with INL R\&D Objective Six Advance the Deployment of Secure and Sustainable Energy Systems

Innovative and Novel:

- Develop a prototype battery stateof-health metric based on passive and active measurements

- Demonstrate the ability to adapt behaviors for extended life and increased resilience
Technical Impact:

- Proof of principle on a framework for a state-of-health assessment using the novel in-situ rapid impedance spectrum measurement technique combined with standard battery parameters

- Development of smart algorithms for directly estimating state-ofcharge based on impedance spectral measurements

- Presented at national and international conferences

- Peer review publication in process

- Review by two external peer advisory committees. It was noted that the project addresses the grand challenges of future resilient control systems to enable improved energy security

Collaboration:

- Montana Tech 
5. LDRD PROGRAM ORGANIZATION AND RESPONSIBILITIES

The LDRD Program Office reports to the INL DLD for Science and Technology. The LDRD Program Office includes a Program Manager and a Program Coordinator who are responsible for managing and reporting on the various LDRD processes. These responsibilities include producing the annual Report to Congress, writing plans, completing assessments, delivering project data sheets to DOE-ID, generating responses for information requests for the program, supporting LDRD reviews, participating in oversight activities, contributing to LDRD working groups, and maintaining documentation. The LDRD Program Office works in close collaboration with the MAPOCs. The MAPOCs are appointed by the DLD or an appropriate ALD to assist in managing one of the portfolio focus areas. The LDRD Program Office and the MAPOCs ensure that Calls are consistent with the strategic direction of the Laboratory and that quality technical peer review and management reviews are conducted. The MAPOCs include senior managers, initiative leaders, and senior research staff who are also involved in strategic planning and assessment for the Laboratory. The MAPOCs are represented in each of the portfolio focus areas highlighted in section 4.2 .

\subsection{Project Evaluation, Selection, and Review}

INL solicits proposals for LDRD projects through an annual Call for proposals (i.e., "the Call"). The Call takes into consideration the need to support key technical capability development, collaboration with university and industry partners, and other crucial research, including enabling or crosscutting science. These solicitations encourage innovative approaches proposed by individual researchers or small multidisciplinary teams. There are three potential routes to access LDRD funding through the Call, as shown in Table 2.

The Call requests a preproposal followed by a written full proposal, a technical peer review, and a management review prior to project selection (see Figure 2). Preproposals are two-page white papers that stimulate broad input from the research community. The intent of the preproposal process is to provide principal investigators the opportunity to briefly articulate an idea and have management review for interest, prior to investment of time and effort to write a full proposal. Detailed full proposals are then prepared, which are subject to technical peer and management review. A data sheet for selected projects is then provided to DOE-ID for concurrence. LDRD projects are authorized to start work at the onset of the new FY following receipt of DOE-ID's concurrence, and DOE-NE's approval of the annual LDRD Program Plan.

\subsubsection{Technical Evaluation of Proposals}

All LDRD proposals undergo both technical peer and management review for prioritization in meeting DOE and INL strategic needs. The technical peer review process ensures research of sound technical merit is funded and criteria specified in DOE Order 413.2B "Laboratory Directed Research and Development" are met. The LDRD Program Office oversees directorateled teams to conduct technical reviews of proposals through establishment of technical review committees. The technical review committees may include members of management, technology transfer, legal, and peers from other INL organizations along with at least two reviewers with the appropriate technical expertise and professional stature to critically evaluate proposals. External technical reviewers from universities or industry are used as needed to provide required expertise and/or to avoid conflict of interest. The LDRD Program Office works with the directorateled teams to address any conflict of interest concerns that may develop from internal or external reviewers. Technical review evaluation criteria are established and published in the Call. A technical review sub-chairperson collects individual proposal evaluations from reviewers, and explains/resolves discrepancies among individual evaluations. The results of the technical review are provided to the LDRD Program Manager and the appropriate LDRD MAPOC. The proposal authors are given the opportunity to review evaluation results. Questions or concerns about accuracy or fairness 


\section{IDAHO NATIONAL LABORATORY • PLN 3872}

of the review may be addressed via the LDRD Program Office and the directorate-led teams. Anonymity of individual reviewers is preserved.

For the FY 2014 technical review process, in a limited setting, INL is exploring the use of a brief oral presentation by the Principal Investigator to a technical review committee. This approach is being evaluated at the request of INL principal investigators, who indicated it would be beneficial to have the opportunity to present their research ideas orally in addition to the written proposal. This gives the principal investigators the opportunity to explain their research concept and answer questions/concerns that may come up on a real-time basis. Other national laboratories have successfully implemented this approach. After this review cycle, the LDRD Program Office will evaluate the value, success, and concerns associated with this approach. This concept will be used for the FY 2014 Call for proposals for the Crosscutting Capability Development portfolio.

\subsubsection{Management Evaluation of Proposals}

The LDRD MAPOCs ensure alignment of LDRD research projects with the DOE-NE and Laboratory strategic needs. These individuals have current knowledge from strategic and research planning for the Laboratory. In a process that is independent from the technical peer review, the ALD, MAPOC, appropriate managers and senior technical staff review the proposals against criteria designed to evaluate consistency with strategic direction and value to INL. The management team is familiar with the direct-funded DOE work and Work-forOthers that is being conducted at INL to ensure compliance with DOE Order 413.2B. Thus, the management team is in a position to evaluate whether the proposal is duplicative of work being conducted elsewhere, or if the proposed research is in a subject area specifically prohibited by Congress or DOE. Such proposals would not be eligible for LDRD funding. The MAPOC submits the management reviews and projects selected for funding to the LDRD Program Office.

\subsubsection{Project Selection and Approval}

The LDRD Program Office integrates the results of the INL technical and management reviews into the final LDRD portfolio. Each portfolio element is provided to the responsible ALD or MAPOC for approval of the proposed LDRD research projects. Once approved, project data sheets are submitted to DOE-ID for concurrence.

DOE-ID reviews the submitted LDRD research projects to ensure alignment with the missions of DOE and for compliance with Federal legislation,

Table 2. The INL LDRD Call routes to access LDRD funding.

\begin{tabular}{l|l}
\hline Type & Call \\
\hline Open & - Solicits research proposals from INL scientific and engineering community \\
& $\begin{array}{l}\text { - Encourages collaboration with national and international universities, including National } \\
\text { University Consortium (NUC) and Idaho University Consortium (IUC) partners }\end{array}$ \\
\hline - Promotes a broad pool of innovative approaches to the technical challenges contained in the Call \\
\hline Directed & $\begin{array}{l}\text { Invited research proposal-the lead proposal writer, the broad research area, and the approximate } \\
\text { level of effort are specified }\end{array}$ \\
\hline - Multidisciplinary teams are sought to engage with the identified lead \\
- Subject to the same level of rigor for technical peer review and management review \\
\hline $\begin{array}{l}\text { - Multiyear (2-3 years) scope of work, passed technical peer review (not to exceed a } \\
\text { 36-month term) } \\
\text { - Performance expectations are met (i.e., strategy, publications, cost, schedule, and budget) } \\
\text { - Concurrence by DOE-ID }\end{array}$
\end{tabular}




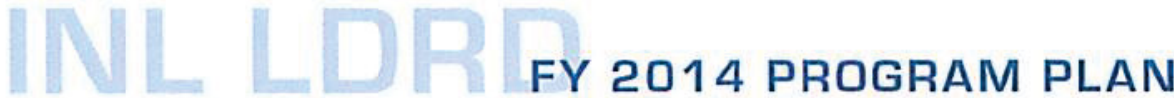

DOE Orders, and supporting directives. Concerns or issues are resolved with the LDRD Program Office prior to the announcement of winning proposals and the initiation of the research projects. DOE-ID concurs on the new and continuing LDRD research projects.

\subsubsection{Review of Research Progress}

At least once during the FY, the responsible ALD works with the appointed LDRD MAPOC, appropriate managers, and technical staff to review the LDRD research projects. The objectives of the reviews are to evaluate progress, identify potential concerns, and suggest corrective actions as appropriate. The MAPOC evaluates projects for eligibility to continue into the subsequent FY. Redirection of funds may occur due to inability to meet proposed objectives, if data collected suggest new approaches, or higher value topics arise. Individual LDRD projects may be reviewed by organizational external peer advisory committees for alignment of the projects with mission and vision, development of differentiating capabilities, innovation, and technical progress.

\subsection{Reporting}

\subsubsection{Monthly and Quarterly Budget Reports}

The LDRD Program Coordinator prepares a monthly financial report for each research project in the LDRD portfolio. This monthly report is distributed to the project principal investigator, MAPOC, and other appropriate managers in an effort to track expenditures, manage budgets, and align project schedule. A quarterly financial report is provided to DOEID and other financial information is provided on an ad-hoc basis.

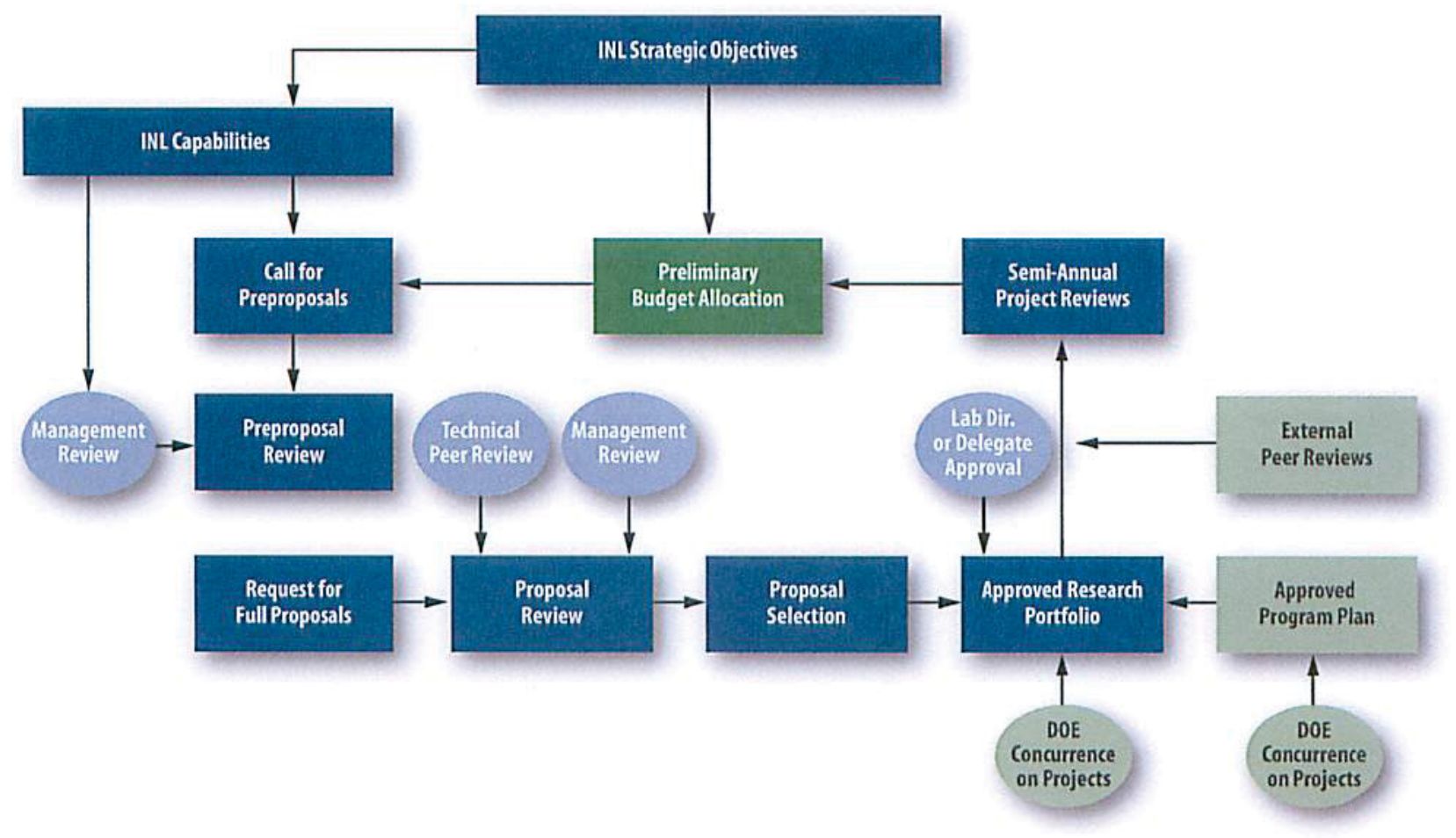




\section{IDAHO NATIONAL LABORATORY • PLN 3872}

\subsubsection{Annual Report}

An annual report is required for each research project funded by the LDRD program. An INL LDRD Program Annual Report is compiled from individual project summaries and is distributed to DOE-ID, DOE-NE, Office of Scientific and Technical Information, and INL managers within six months after the end of each FY. INL adopted a revised format for the FY 2012 Annual Report, referred to as the LDRD Snapshot. The Snapshot provides a concise and manageable format to deliver a summary presentation of the required elements per DOE Order 413.2B and the Roles and Responsibilities Guidelines. Additionally, the LDRD Snapshot includes a glimpse into the diverse R\&D portfolio, calling out select projects to communicate the impact of our LDRD portfolio that includes

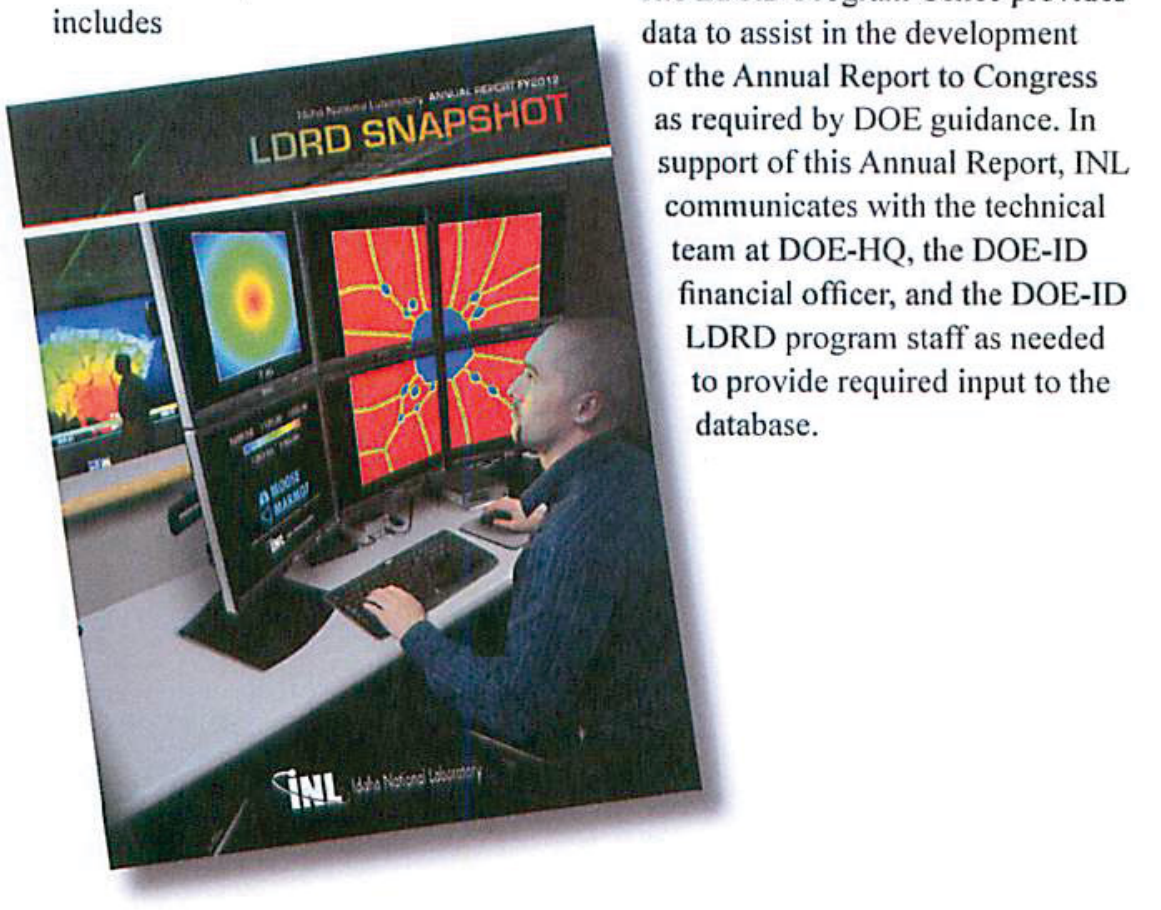

success stories, program metrics, awards, and university collaborations, as well as individual LDRD project summaries (in CD format).

\subsubsection{Annual Program Review}

The LDRD Program Office coordinates with DOE-ID and DOE-NE to prepare and conduct an annual INL LDRD

Program Review - locations vary to accommodate DOE and other Laboratory integration interests. In FY 2013, the INL presented a business review of the FY 2012 and preliminary FY 2013 program processes and metrics at DOE-HQ in June, followed by a technical program review of select LDRD projects at DOE-HQ in July.

\subsubsection{Annual Report to Congress and Notification to Other Federal Agencies}

The LDRD Program Office provides data to assist in the development of the Annual Report to Congress ce. In ort, INL financial officer, and the DOE-ID needed input to the 


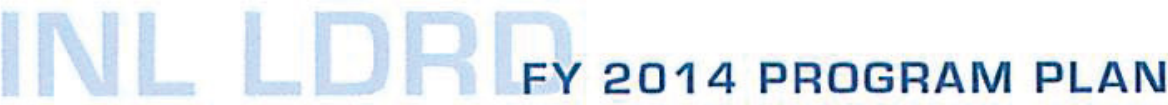

\subsection{LDRD Program Self-Assessment}

The INL LDRD Program Office completes an annual LDRD program assessment to systematically consider past assessments, current performance metric information, and complementary information from external peer advisory committee reviews and internal project reviews. This assessment is used to support management decisions, provide information for required reports, ensure program compliance to DOE requirements, and continually ensure the LDRD program is effectively supporting the INL mission. This year's program assessment identified the following actions for the LDRD Program Office:
- Need to increase LDRD publication, student, and postdoctoral numbers: In FY 2014, INL has added an internal LDRD publication requirement within certain portfolio areas. LDRD projects seeking continuation into the second and third year are encouraged to produce at least one peer-reviewed publication or presentation each year of continuation. Goals will be set for project outcomes for each portfolio to include metrics deemed essential by the MAPOCs, including, where appropriate, numbers of students and postdocs.

- Enhance communication of the LDRD Program: We are utilizing a revised format for the INL LDRD Program Report and are providing project highlights to $\mathrm{DOE}$ counterparts on a periodic basis to demonstrate the diversity, technical significance, and R\&D outcomes within the INL LDRD portfolio.

- Increase awareness of the INL LDRD Program: We have developed an external web portal dedicated to the INL LDRD program to communicate goals, benefits, awards, and scientific outcomes of the INL LDRD portfolio.

- Communicate R\&D outcomes of INL LDRD Program: Technical presentations were provided for several LDRD projects as part of the INL LDRD Program Review at DOE-NE office buildings to enable engagement and participation of key personnel.

Table 3. Approximate dates of INL technical project activities in FY 2014.

\begin{tabular}{l|l}
\hline Month & Activity \\
\hline October 2013 & Authorize and initiate continuing and new FY 2014 LDRD projects \\
\hline February-March 2014 & Conduct ongoing LDRD project progress reviews \\
\hline March 2014 & Issue the FY 2015 LDRD Call for Proposals \\
\hline June-July 2014 & Complete technical and management reviews of FY 2015 LDRD project proposals \\
\hline August 2014 & Conduct external peer advisory committee reviews \\
\hline July-August 2014 & Conduct ongoing LDRD project progress reviews \\
\hline October 2014 & Authorize and initiate continuing and new FY 2015 LDRD projects \\
\hline
\end{tabular}

Table 4. Dates of INL program management activities.

\begin{tabular}{l|l}
\hline Month & Activity \\
\hline October 2013 & Upload the FY 2013 LDRD program data to the chief financial officer database \\
\hline November 2013 & Provide narrative input for the Annual Report to Congress \\
\hline February-March 2014 & Establish forum and venue for annual Program Review \\
\hline March 2014 & Issue the FY 2013 LDRD Program Annual Report \\
\hline May 2014 & Develop content and context revisions for the FY 2015 Program Plan \\
\hline June 2014 & Submit the Draft FY 2015 LDRD Program Plan for review to DOE-ID on June 30, 2014 \\
\hline June-July 2014 & Conduct or participate in the annual LDRD Program Review prior to July 30, 2014 \\
\hline August 2014 & Ensure the Final FY 2015 LDRD Program Plan is submitted for approval prior to August 15, 2014 \\
\hline
\end{tabular}




\section{IDAHO NATIONAL LABORATORY • PLN 3872}

The DOE-NE "Roles and

Responsibilities Guidelines for Laboratory Directed Research and Development at INL," issued January 6,2009 , identifies annual performance indicators. This information is collected directly from INL enterprise systems (see Table 5).

The LDRD program performance indicators provide direct evidence of the impact LDRD plays in supporting the DOE-NE mission and underlying multiprogram capabilities benefiting INL's research, development, demonstration, and deployment mission. LDRD contributes to building personnel capability by providing funding for postdoctoral students, interns, and new hires. The new hires are typically external hires in strategic areas where INL is growing a specific capability. The LDRD publication record demonstrates projects are technically sound and accepted by peers as novel, significant, and technically relevant. Evidence of supporting and developing INL's technology capability and infrastructure is shown in the invention disclosures and patent metrics.
The award metric is direct evidence that LDRD supports creative and innovative technologies that enhance INL's reputation as leading programs of national significance. In FY 2012, INL is pleased to receive recognition for the technical achievements of the LDRD project Cognitive Intelligent Wireless Communications R\&D (WsComm) (10-075) as a recipient of the 2012 R\&D 100 Award.

The LDRD innovation delivers a unique communication control channel "breakthrough" that narrows an existing technology gap in current radio frequency management of voice, video, and data communications.

The R\&D 100 Award is a highly coveted international award provided from R\&D Magazine in their annual competition for the top 100 technologies in the world. This technology also received a Far West Federal Laboratory Consortium and Idaho Innovation Award. WsComm also earned the Best Demonstration award at the 2012 DySpan Conference, IEEE's (Institute of Electrical And Electronics Engineers) leading international conference dedicated to advancing cutting-edge wireless technologies.

Derek Gaston, an INL computational mathematician, was one of 96 recipients of the 2012 Presidential Early Career Award for Scientists and Engineers. The award is the highest honor the U.S. Government bestows on early career science and engineering professionals. As the Computational Frameworks Group Lead for INL's Fuels Modeling and Simulation Department, Derek Gaston lead the development of the MOOSE simulation framework, which was LDRD-funded and underlies several current LDRD projects.

In FY 2012, the INL LDRD portfolio maintained the number of university collaborations. The collaborations resulted in greater than 100 university collaborations in the FY 2012 LDRD portfolio, which supported faculty and students at numerous universities, including eight postdoctoral fellows and 12 student interns at the INL. In addition, one new Science and Engineering hire in FY 2012 was supported with LDRD funding. The

Table 5. LDRD program performance indicators for required reporting years.

\begin{tabular}{|c|c|c|c|c|c|c|c|c|}
\hline $\begin{array}{l}\text { Fiscal } \\
\text { Year }\end{array}$ & Postdoctoral & Students & $\begin{array}{l}\text { New S\&E } \\
\text { Hires }\end{array}$ & Publications & IDRs & Patents & $\begin{array}{l}\text { National/ } \\
\text { International } \\
\text { Awards }\end{array}$ & Copyrights \\
\hline 2012 & 8 & 12 & 1 & 62 & 19 & 4 & 2 & 1 \\
\hline 2011 & 17 & 21 & 10 & 62 & 18 & 12 & 5 & 0 \\
\hline 2010 & 10 & 43 & 21 & 54 & 15 & 14 & 1 & 0 \\
\hline 2009 & 11 & 24 & 14 & 65 & 11 & 3 & 0 & 0 \\
\hline
\end{tabular}




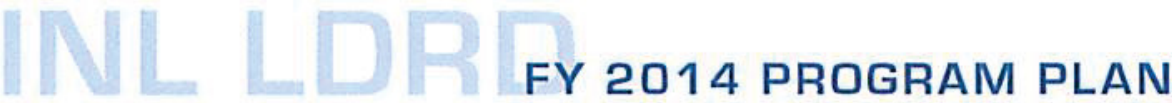

INL LDRD program's research resulted in 62 peer-reviewed publications and conference presentations in FY 2012. In addition, LDRD principal investigators submitted 19 invention disclosure records, while four patents were awarded to research projects attributed to LDRD efforts.

Trends across any of these performance metrics are not easily determined due to variables of total LDRD funding levels, total direct-funding levels within the R\&D programs, evolving mission objectives, and maturity cycles of the specific projects. Without doubt, the general steady-state performance of these metrics is clear evidence the LDRD program contributes to INL's national nuclear mission of addressing current and future DOE science and infrastructure capability.

The performance metrics for FY 2013 will continue to provide guiding objectives for the LDRD program and selected portfolio projects as the performance metrics continuously ensure INL strategic alignment for proposal objectives, provide accountability to technical relevance, demonstrate collaborative involvement, and validate partnership opportunities. Since LDRD is the primary source of discretionary research funding utilized to leverage and advance the INL's mission, our intent is to continuously evaluate performance metrics that will assist INL in improving the LDRD program.
The LDRD program performance measures provide

direct evidence of the impact LDRD plays in supporting

the DOE-NE mission and underlying multiprogram

capabilities benefiting INL's research, development, demonstration, and deployment mission. 
www.in I.gov
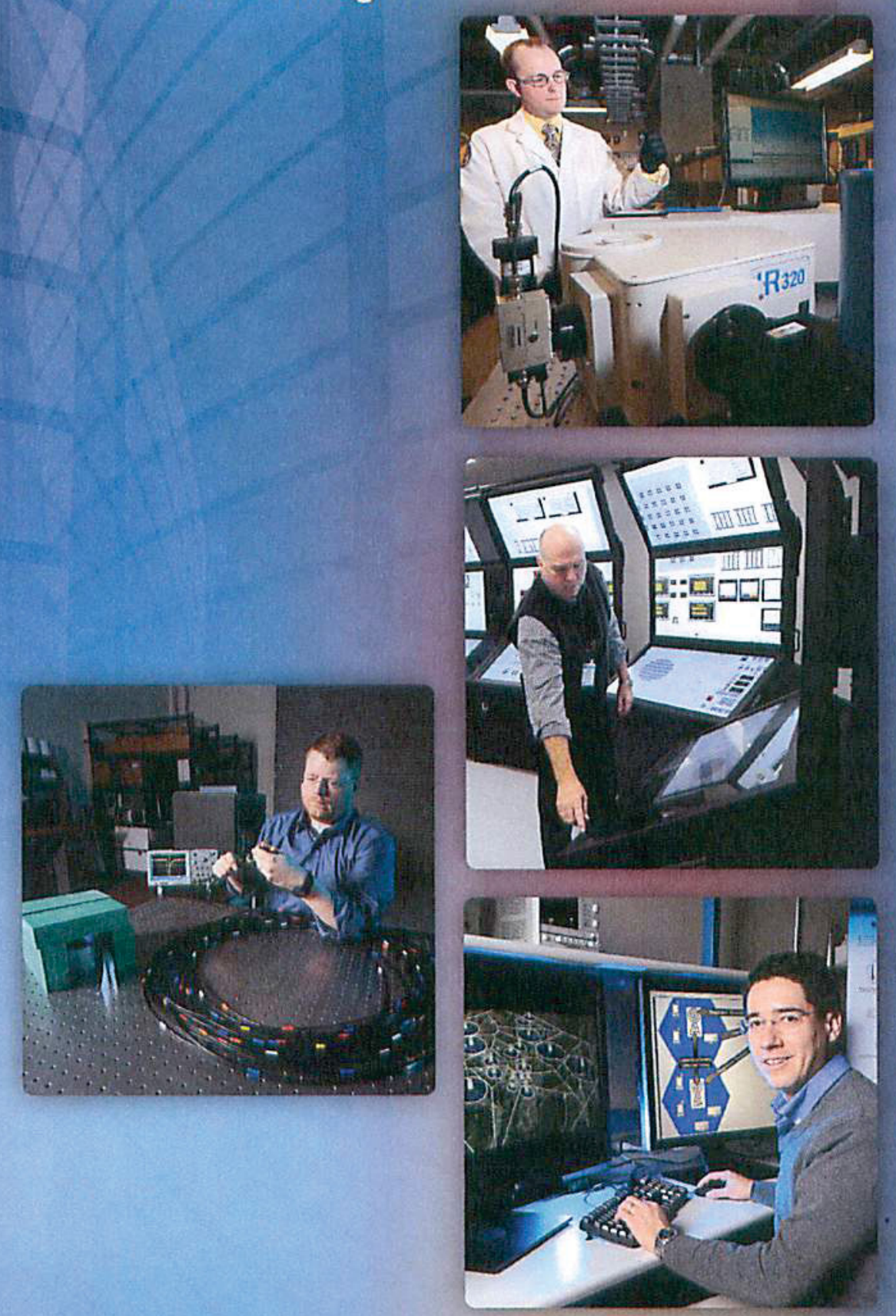

Idaho National Laboratory

(0) ENERGY 